\title{
Patterns of statin initiation and continuation in patients with breast or colorectal cancer, towards end-of-life
}

\author{
Amelia Smith $^{1,2}$ - Laura Murphy ${ }^{3}$ Kathleen Bennett ${ }^{3}$ - Thomas I Barron ${ }^{1,4}$
}

Received: 12 July 2016 / Accepted: 9 January 2017 /Published online: 18 January 2017

(C) The Author(s) 2017. This article is published with open access at Springerlink.com

\begin{abstract}
Purpose Cross-sectional studies show that statins, used in cardiovascular disease prevention, are often discontinued approaching death. Studies investigating associations between statin exposure and cancer outcomes, not accounting for these exposure changes, are prone to reverse causation bias. The aim of this study was to describe longitudinally the changes in statin initiation and continuation prior to death in patients with breast or colorectal cancer, thus establishing an appropriate exposure lag time.

Methods This study was carried out using linked cancer registry and prescribing data. We identified patients who died of their cancer (cases) and cancer survivors were used as controls. The probability of initiating or continuing statin use was estimated up to 5 years prior to death (or index date). Conditional binomial models were used to estimate relative risks and risk differences for associations between approaching cancer death and statin use.
\end{abstract}

Electronic supplementary material The online version of this article (doi:10.1007/s00520-017-3576-0) contains supplementary material, which is available to authorized users.

Amelia Smith

smitha25@tcd.ie

1 Trinity Centre for Health Sciences, Trinity College, University of Dublin, Dublin, Ireland

2 Department of Pharmacology \& Therapeutics, Trinity Centre for Health Sciences, St James's Hospital, Dublin 8, Ireland

3 Division of Population Health Sciences, Royal College of Surgeons in Ireland, Dublin, Ireland

4 Johns Hopkins Bloomberg School of Public Health, Baltimore, MD, USA
Results Compared to controls, the probability of continued statin use in breast cancer cases was significantly lower 3 months prior to death (RR $0.8695 \%$ CI $0.79,0.94$ ). Similarly, in colorectal cancer cases, the probability of continued statin use was significantly lower 3 months prior to colorectal cancer death (RR 0.77 95\% CI 0.68, 0.88).

Conclusion A significant proportion of patients will cease statin treatment in the months prior to a colorectal or breast cancer death.

Keywords Breast cancer $\cdot$ Colorectal cancer $\cdot$ Statins . End-of-life $\cdot$ Epidemiology

\section{Background}

In patients with reduced life expectancy, such as after a diagnosis of metastatic cancer, there may be a substantial increase in pharmacotherapeutic burden [1]. Approaching end-of-life, there can often be a treatment paradigm shift to that of palliative care. Accordingly, medications prescribed to patients with advanced cancer may be reviewed regularly and those unlikely to provide benefit, or those associated with increased risk of side-effects, can be discontinued [1]. Statins, or 3hydroxy-3-methylglutaryl-CoA reductase inhibitors, are used in the primary prevention of cardiovascular disease, with treatment benefits accruing over at least 2 years [2]. In patients with established cardiovascular disease, statins may be used as secondary prevention through long-term lipid lowering, and short-term anti-inflammatory effects [3]. Therefore, the potential benefit of statin use in those with reduced life expectancy may be limited to high-risk patients [4], and should be considered for discontinuation in those who are unlikely to benefit. 
Several studies have investigated statin use in those with reduced life expectancy, which suggest that many patients will cease statin treatment by the time of death [5-9]. However, these are largely cross-sectional studies reporting statin exposure at the time of death. Observational studies investigating the association between statin exposure and cancer outcomes, not accounting for changes in statin utilization towards the end-of-life, are likely to be associated with reverse causation bias. This occurs when changes in prognosis or disease status lead to a change in the exposure of interest. There is little empirical evidence informing the choice of an appropriate exposure lag time for adjusting for reverse causation bias, as investigators do not always have a priori assumptions based on biological evidence [10]. There is little data to describe the changes in statin exposure longitudinally prior to death, which is vital for determining an appropriate exposure lag period.

Two of the most prevalent invasive cancers are breast and colorectal cancer [12]. Therefore, the aim of this study was to describe the changes in statin exposure longitudinally prior to death in patients in Ireland with breast or colorectal cancer which are, in particular, to (i) estimate the probability of initiating statin therapy in the 5 years prior to a death from cancer, (ii) estimate the probability of continuing statin-use towards end-of-life, and (iii) compare these longitudinal statin exposures with statin exposures measured in matched cancersurvivors over the same time period, thus establishing an appropriate statin exposure lag time.

\section{Methods}

\section{Setting and data Sources}

This study was carried out using individual-level patient records from the National Cancer Registry Ireland (NCRI), which are linked to prescription dispensing records from Ireland's Health Services Executive (HSE) Primary Care Reimbursement Services (PCRS) pharmacy claims database. These linked datasets have been described previously [13]. Briefly, the NCRI records details about all cancers diagnosed in the population normally resident in Ireland. For each tumor diagnosed, hospital-based tumor registration officers (TRO) collect information on patient and tumor characteristics, and treatment received. Information on mortality, date, and cause of death are obtained from linked death certificates. The completeness of NCRI data has been evaluated and is estimated to be at least $95 \%$ for breast cancer, and $96 \%$ for colorectal cancer [14]. The use of anonymized data held by the NCRI is covered by the Health (Provision of Information) Act 1997.

The PCRS is responsible for financial reimbursement of dispensed medication claims made under the General Medical Services (GMS) community drug scheme. The GMS scheme provides subsidized healthcare, including prescription medications at no or minimal cost, to approximately one third of the Irish population, with eligibility assessed by a combination of means test and age ( $\geq 70$ years). The PCRS pharmacy claims database records all drugs dispensed under the GMS scheme; this includes all statin prescriptions which are not available over-the-counter in Ireland. Drugs are coded according to WHO-ATC classification system [15].

\section{Cohort and exposure definitions}

The study population was defined as all patients diagnosed with stages I-III, invasive breast (ICD-10 C50) or colorectal cancer (ICD-10 C18-C20), between 1 January 2001 and 31 December 2009, with continuous eligibility for the GMS scheme starting at least 1 year prior to diagnosis. Patients with prior invasive cancers (other than non-melanoma skin cancer) were excluded, as were men with a diagnosis of breast cancer.

From this defined study population, we identified patients who died of their cancer (cases) between 1 January 2001 and 31 December 2009, using SEER definitions for breast and colorectal cancer-specific death [16]. Patients who were alive on 31 December 2011 were identified as cancer survivors, and were used as controls. Using a greedy matching algorithm [17], controls were matched to cases separately for breast (2:1) and colorectal cancer (1:1), by tumor stages (I, II, III), age at diagnosis (5 year caliper), gender (colorectal cancer only), and pre-diagnostic statin use (yes/no). Where cases have pre-diagnostic statin exposure, we also matched controls on the intensity of statin exposure in the year prior to diagnosis (10\% caliper). The date of death for each case was used as an index date for matched controls and a reference point to calculate statin exposure.

All prescriptions for statins were identified using the PCRS database; drugs are coded using WHO-ATC drug classifications [15](Online Resource 1). We used the dose and number of days' supply on each statin prescription to establish longitudinal exposure histories for each patient by assigning the days' supply from each prescription (normally of 1 month duration) to sequential days from the date of dispensing [18].

For cases and matched controls, we used these statin exposure histories to calculate measures of statin use in sequential pre-defined exposure windows starting at date of death for cases, or index date for controls, and continuing up to diagnosis, or for a maximum of 5 years (whichever comes first). We chose a duration of maximum 5 years prior to death as the median survival post breast or colorectal cancer recurrence which is $2-2.5$ years $[19,20]$. First, we identified patients without statin exposure prior to diagnosis who initiated statin treatment in the time post-diagnosis within each exposure window. Second, for those patients with statin exposure prior to diagnosis, we identified patients with a supply of statins during each exposure window. From these pre-mortality 
Fig. 1 Study flow diagram

measures of statin exposure, we estimated, for each exposure window, (i) the probability of starting statin use as death approached, and (ii) the probability of continuing statin use towards end-of-life.

\section{Statistical analyses}

The frequency of cases and controls were tabulated by clinical and socio-demographic characteristics. Descriptive statistics were weighted by the inverse number of controls matched to each case, and standardized differences were used to assess balance $(\mathrm{d}<0.1)$ in the matched covariates [17]. The probability of (i) statin initiation and (ii) maintaining statin use in each exposure window were plotted for cases and matched controls with respect to the length of time prior to death/ index date. Smoothing splines were fitted with locally weighted error sum of squares of regression [21].

Conditional binomial models were used to estimate relative risks (RR) and risk differences (RD) with $95 \%$ confidence intervals (CI) for (i) initiating statin treatment and (ii) continuing statin use in cases versus controls. These analyses were carried out for statin exposure immediately prior to death/ index date, and repeated for consecutive preceding windows. All analyses were performed with SAS $®$, version 9.3 (SAS ${ }^{\circ}$ Institute Inc., Cary, NC). Results were considered statistically significant at a two-sided $\alpha$-level of 0.05 .
Breast cancer

Women with invasive breast cancer 1/2001 - 12/2009. Excluding diagnosed at death.

$\mathbf{N}=\mathbf{1 9 , 8 0 4}$

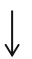

Services eligibility from prior to diagnosis $\mathbf{N}=\mathbf{1 0 , 3 1 9}$

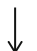

east cancer at diagnosis

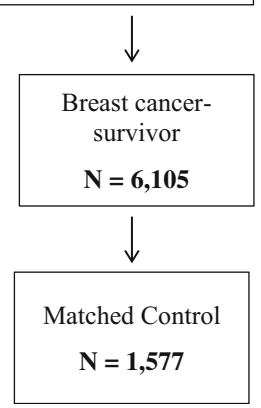

Colorectal cancer

Women/men with invasive colorectal cancer diagnosed 1/2001 - 12/2009. Excluding prior invasive cancer, or colorectal cancer diagnosed at death.

$N=18,243$

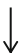

General Medical Services eligibility from one year prior to diagnosis $\mathbf{N}=\mathbf{1 2 , 6 7 0}$

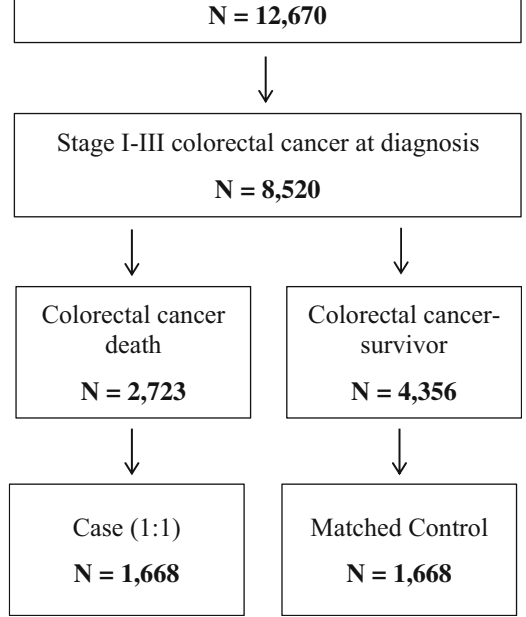

\section{Results}

\section{Study population}

The selection of breast $(N=8711)$ or colorectal cancer $(N=8520)$ patients from the NCRI database is shown in a flow diagram (Fig. 1), and the patient characteristics are shown in Table 1 . The median age at diagnosis of patients with breast or colorectal cancer was 69 and 75 years respectively, and $28.8 \%$ of breast and $11.5 \%$ of colorectal cancer patients were taking statins in the year prior to cancer diagnosis. From these breast and colorectal cancer cohorts, we matched 1055 breast or 1688 colorectal cancer cases (deaths) to 1557 and 1668 cancer controls (survivors), respectively.

\section{Statin initiation approaching end of Life}

The results from conditional bionomial model analyses investigating statin initiation in the 5 years prior to death/index date are shown in Online Resources 2 and 3. Rates of statin initiation did not seem to differ as breast or colorectal cancer patients approached end of life. In the 6 months prior to death/index date, $1.4 \%$ of breast and $1.2 \%$ of colorectal cases initiated statin use, as compared to $2.1 \%$ and $1.4 \%$ of controls, respectively. 
Table 1 Characteristics of matched cases and controls - breast cancer and colorectal cancer

\begin{tabular}{|c|c|c|c|c|c|c|c|}
\hline \multirow[t]{2}{*}{ Characteristic } & & \multicolumn{3}{|c|}{ Breast cancer } & \multicolumn{3}{|c|}{ Colorectal cancer } \\
\hline & & $\begin{array}{l}\text { All } \\
N=8711\end{array}$ & $\begin{array}{l}\text { Breast } \\
\text { cancer } \\
\text { death } \\
N=1055\end{array}$ & $\begin{array}{l}\text { Matched } \\
\text { control }^{\mathrm{a}, \mathrm{b}, \mathrm{c}} \\
N=1577\end{array}$ & $\begin{array}{l}\text { All } \\
N=8520\end{array}$ & $\begin{array}{l}\text { Colorectal cancer death } \\
N=1668\end{array}$ & $\begin{array}{l}\text { Matched control }{ }^{\mathrm{a}, \mathrm{b}} \\
N=1668\end{array}$ \\
\hline \multicolumn{8}{|l|}{ Matched covariates } \\
\hline \multicolumn{2}{|l|}{$\begin{array}{l}\text { Age in years-Median } \\
(\mathrm{IQR})^{\mathrm{d}}\end{array}$} & $69(57.77)$ & $71(58.78)$ & $70(59.77)$ & $75(70.80)$ & $75(69.79)$ & $74(68.78)$ \\
\hline \multirow[t]{3}{*}{ Tumor stage $-N(\%)^{\mathrm{e}}$} & I & $2651(30.4)$ & $141(13.3)$ & $244(13.3)$ & $1546(18.2)$ & $184(11.0)$ & $184(11.0)$ \\
\hline & II & $4603(52.9)$ & $623(59.1)$ & $995(59.1)$ & $3608(42.3)$ & $756(45.3)$ & $756(45.3)$ \\
\hline & III & $1457(16.7)$ & $291(27.6)$ & $338(27.6)$ & $3366(39.5)$ & $728(43.7)$ & $728(43.7)$ \\
\hline \multicolumn{2}{|c|}{ Pre-diagnostic statin use $-N(\%)^{\mathrm{f}}$} & $2508(28.8)$ & $248(23.5)$ & $377(23.5)$ & $977(11.5)$ & $198(11.9)$ & $198(11.9)$ \\
\hline \multicolumn{2}{|c|}{$\begin{array}{l}\text { Pre-diagnosis statin intensity-Mean } \\
(\mathrm{SD})^{\mathrm{f}}\end{array}$} & $0.77(0.3)$ & $0.77(0.32)$ & $0.77(0.26)$ & $0.73(0.32)$ & $0.74(0.32)$ & $0.75(0.32)$ \\
\hline \multicolumn{2}{|c|}{ Gender Male- $N(\%)$} & - & - & - & $4682(54.9)$ & $915(54.9)$ & $874(52.4)$ \\
\hline \multicolumn{8}{|l|}{ Unmatched covariates } \\
\hline \multirow[t]{4}{*}{ Treatments - $N(\%)^{\mathrm{g}}$} & Chemotherapy & $3260(37.4)$ & $449(42.6)$ & $772(49.0)$ & $2697(31.7)$ & $570(34.1)$ & $745(44.6)$ \\
\hline & Radiation & $5355(61.5)$ & $566(53.7)$ & $1102(69.9)$ & $1370(16.1)$ & $370(22.2)$ & $260(15.6)$ \\
\hline & Surgery & $7487(86.0)$ & $803(76.1)$ & $1480(94.9)$ & 7971 (91.4) & $1362(81.7)$ & $1628(97.6)$ \\
\hline & $\begin{array}{l}\text { All three } \\
\text { modalities }\end{array}$ & $2519(29.0)$ & $324(30.7)$ & 624 (39.6) & 885 (10.4) & $204(12.2)$ & $211(12.7)$ \\
\hline \multirow[t]{4}{*}{ Tumor grade $-N(\%)^{\mathrm{d}}$} & 1 & $862(9.9)$ & $30(2.8)$ & $141(8.9)$ & $530(6.2)$ & 80 (4.8) & $104(6.2)$ \\
\hline & 2 & 4275 (49.1) & $369(35.0)$ & $821(52.1)$ & $6017(70.6)$ & $1071(64.2)$ & $1252(45.1)$ \\
\hline & 3 & $2762(31.7)$ & $509(48.3)$ & $504(32.0)$ & 1045 (12.3) & $270(16.2)$ & $184(11.0)$ \\
\hline & Unspecified & $812(9.3)$ & 147 (13.9) & $111(7.0)$ & 900 (10.6) & $247(14.8)$ & $128(7.7)$ \\
\hline \multirow[t]{4}{*}{ Smoking-N $(\%)^{\mathrm{d}}$} & Current & $1747(20.1)$ & $235(22.3)$ & 298 (18.9) & 1165 (13.7) & $282(16.9)$ & $200(12.0)$ \\
\hline & Past & $3993(45.8)$ & $118(11.2)$ & 199 (12.6) & $3415(40.1)$ & $302(18.1)$ & 347 (20.8) \\
\hline & Never & 1004 (11.5) & $437(41.4)$ & 783 (49.7) & $1731(20.3)$ & $640(38.4)$ & 749 (44.9) \\
\hline & Unspecified & $1967(22.6)$ & $265(25.1)$ & $297(18.8)$ & 2209 (25.9) & 444 (26.6) & $372(22.3)$ \\
\hline \multirow{6}{*}{$\begin{array}{l}\text { Deprivation Score- } N \\
(\%)^{\mathrm{d}}\end{array}$} & 1 - Low & $1098(12.6)$ & 133 (12.6) & $207(13.1)$ & $1225(14.4)$ & $211(12.7)$ & $269(16.1)$ \\
\hline & 2 & $954(11.0)$ & $113(10.7)$ & $184(11.6)$ & $926(10.9)$ & $168(10.1)$ & $192(11.5)$ \\
\hline & 3 & $1091(12.5)$ & $129(12.2)$ & $196(12.4)$ & 1157 (13.6) & $255(15.3)$ & $202(12.1)$ \\
\hline & 4 & $1563(17.9)$ & $181(17.1)$ & $297(18.8)$ & $1550(18.2)$ & $300(18.0)$ & $288(16.8)$ \\
\hline & 5 - High & 3428 (39.4) & $424(40.2)$ & $602(38.2)$ & $3163(37.1)$ & $633(38.0)$ & $617(17.3)$ \\
\hline & Unspecified & $577(6.6)$ & $75(7.1)$ & $91(5.8)$ & $499(5.9)$ & $101(6.1)$ & $100(6.0)$ \\
\hline \multicolumn{8}{|c|}{$I Q R$ inter-quartile range, $S D$ standard deviation } \\
\hline \multicolumn{8}{|c|}{$\begin{array}{l}{ }^{b} \text { Matched on tumor stages (I, II, III), age (5-year caliper) and pre-diagnostic statin use (yes/no). Pre-diagnostic statin users were also matched on } t \\
\text { intensity of pre-diagnostic statin exposure ( } 10 \% \text { caliper) }\end{array}$} \\
\hline \multicolumn{8}{|c|}{${ }^{\mathrm{c}}$ Means and percentages for controls were weighted by the inverse number of controls matched to each case } \\
\hline \multicolumn{8}{|c|}{ d At the time of cancer diagnosis } \\
\hline \multicolumn{8}{|c|}{ e AJCC Cancer Staging Manual 6th Edition. Springer, 2002} \\
\hline \multicolumn{8}{|c|}{${ }^{\mathrm{f}}$ In the year pre cancer diagnosis } \\
\hline
\end{tabular}

\section{Continued statin use at end of Life}

In the 5 years prior to death or matched index date, we calculated the proportion of statin users who maintained statin use for both breast and colorectal cancer patients in consecutive time windows, and the results are shown in Tables 2 and Table 3. This data is presented graphically for breast (Fig. 2) and colorectal cancer (Fig. 3). For both breast and colorectal cancer patients, the probability of continuing statin use was comparable in cases and controls up to approximately 1 year 
Table 2 Relative risks and risk differences for continued statin use in five years prior to breast cancer-specific death

\begin{tabular}{|c|c|c|c|c|c|c|}
\hline \multirow{3}{*}{$\begin{array}{l}\text { Statin use within exposure windows } \\
49-60 \text { months prior to death/index }\end{array}$} & \multicolumn{6}{|l|}{ Breast cancer ${ }^{\mathrm{a}, \mathrm{b}}$} \\
\hline & \multirow{2}{*}{$\begin{array}{l}\text { Cases- } N(\text { statin use \%) } \\
26(88.5)\end{array}$} & \multirow{2}{*}{$\begin{array}{l}\text { Controls- } N(\text { statin use } \%)^{\mathrm{c}} \\
31(87.1)\end{array}$} & \multicolumn{2}{|c|}{$\mathrm{RR}(95 \% \mathrm{CI})$} & \multicolumn{2}{|c|}{$\mathrm{RD}(95 \% \mathrm{CI})$} \\
\hline & & & 1.02 & $(0.85,1.21)$ & 0.01 & $(-0.14,0.17)$ \\
\hline 43-48 months prior to death/index & $51(90.2)$ & $65(87.7)$ & 1.03 & $(0.91,1.16)$ & 0.03 & $(-0.08,0.13)$ \\
\hline $37-42$ months prior to death/index & $62(90.3)$ & $82(89.0)$ & 1.01 & $(0.91,1.13)$ & 0.01 & $(-0.08,0.11)$ \\
\hline 33-36 months prior to death/index & $90(87.8)$ & $123(88.6)$ & 0.99 & $(0.90,1.09)$ & -0.01 & $(-0.09,0.07)$ \\
\hline 29-32 months prior to death/index & $110(88.2)$ & $154(90.3)$ & 0.98 & $(0.91,1.05)$ & -0.02 & $(-0.09,0.05)$ \\
\hline 25-28 months prior to death/index & $126(89.7)$ & $175(89.1)$ & 1.01 & $(0.94,1.08)$ & 0.01 & $(-0.06,0.07)$ \\
\hline 22-24 months prior to death/index & $143(88.1)$ & $202(86.6)$ & 1.02 & $(0.95,1.09)$ & 0.01 & $(-0.05,0.08)$ \\
\hline 19-21 months prior to death/index & $160(87.5)$ & $229(85.2)$ & 1.03 & $(0.96,1.1)$ & 0.02 & $(-0.04,0.08)$ \\
\hline 16-18 months prior to death/index & $176(84.7)$ & $258(84.5)$ & 1.00 & $(0.93,1.08)$ & 0.00 & $(-0.06,0.06)$ \\
\hline $13-15$ months prior to death/index & $188(84.0)$ & $278(81.7)$ & 1.03 & $(0.96,1.1)$ & 0.02 & $(-0.03,0.08)$ \\
\hline $10-12$ months prior to death/index & $198(83.8)$ & $294(83.7)$ & 1.00 & $(0.93,1.08)$ & 0.00 & $(-0.06,0.06)$ \\
\hline $7-9$ months prior to death/index & $214(81.3)$ & $321(84.7)$ & 0.96 & $(0.89,1.03$ & -0.03 & $(-0.10,0.03)$ \\
\hline 4-6 months prior to death/index & $224(79.9)$ & $338(83.1)$ & 0.96 & $(0.89,1.04)$ & -0.03 & $(-0.09,0.03)$ \\
\hline 3 months prior to death/index & $234(70.5)$ & $352(81.8)$ & 0.86 & $(0.79,0.94)^{*}$ & -0.11 & $(-0.18,-0.05)^{*}$ \\
\hline 2 months prior to death/index & $238(66.4)$ & $359(82.2)$ & 0.81 & $(0.73,0.89)^{*}$ & -0.16 & $(-0.23,-0.09)^{*}$ \\
\hline 4-3 weeks prior to death/index & $242(56.6)$ & $365(79.5)$ & 0.71 & $(0.63,0.80)^{*}$ & -0.23 & $(-0.30,-0.16)^{*}$ \\
\hline 2 weeks prior to death/index & $245(50.2)$ & $371(77.1)$ & 0.65 & $(0.57,0.74)^{*}$ & -0.27 & $(-0.34,-0.2)^{*}$ \\
\hline 1 week prior to death/index & $247(45.7)$ & $375(76.5)$ & 0.60 & $(0.52,0.69)^{*}$ & -0.30 & $(-0.38,-0.23) *$ \\
\hline
\end{tabular}

$* P<0.05$

${ }^{a}$ Breast cancer cases and cancer-controls matched in ratio of 1:2

${ }^{\mathrm{b}}$ Matched on tumor stages (I, II, III), age (5-year caliper) and pre-diagnostic statin use (yes/no). Pre-diagnostic statin users were also matched on the intensity of pre-diagnostic statin exposure (10\% caliper). Colorectal cancer patients are also matched on gender (male, female)

${ }^{\mathrm{c}}$ Percentages for controls were weighted by the inverse number of controls matched to each case

prior to death/index date. Subsequently, statin use declined for cancer cases when compared to matched cancer survivors. When compared to matched controls, the probability of continued statin use in breast cancer cases was significantly lower from 3 months prior to death (RR $0.8695 \%$ CI 0.79 , 0.94)(Table 2). In colorectal cancer cases, when compared to matched controls, the probability of continued statin use was lower from 12 months prior to death (RR $0.9095 \%$ CI 0.81 , 1.00), and significantly lower at 3 months prior to death from colorectal cancer (RR 0.77 95\% CI 0.68, 0.88)(Table Table3).

In the week prior to death, the probability of continued statin use was $45.7 \%$ for breast cancer cases, compared to $76.5 \%$ of breast cancer controls (RR $0.6095 \%$ CI 0.52, 0.69 ), and $30.8 \%$ for colorectal cancer cases versus $77.4 \%$ for cancer controls (HR $0.4095 \%$ CI 0.32, 0.49).

\section{Discussion}

This study aimed to describe changes in statin exposure prior to death from breast or colorectal cancer; the probability of continuing statin use was found to be significantly lower in the
3 to 6 months prior to death from these cancers. This decline in statin use may be the result of a change in the health care priorities of the patient, and/or reduction in the pharmacotherapeutic burden [22]. In contrast, the number of patients initiating statin use did not differ between those who died of their cancer and those who did not. This suggests that a life-limiting diagnosis does not affect the prescribing of preventative medications.

Several studies have investigated statin use in those with reduced life expectancy $[4,5,7,9,11]$. In the time since these articles were published, a randomized study of statin discontinuation in the palliative care setting was carried out [23]. This study showed that stopping statin therapy in patients with a limited life expectancy was safe for the patients, with no significant difference in the time to cardiac event, and may be associated with improved quality of life [23]. Although there are currently no clinical guidelines on ceasing statin treatment, this clinical trial suggests that it is safe to do so in patients with limited life expectancy. In addition, Lindsay et al. have developed deprescribing guidelines (OncPal) for oncological palliative care in an Australian tertiary hospital setting, and they suggest statins as a potentially inappropriate 
Table 3 Relative risks and risk differences for continued statin use in 5 years prior to colorectal cancer-specific death

\begin{tabular}{|c|c|c|c|c|c|c|}
\hline \multirow{3}{*}{$\begin{array}{l}\text { Statin use within exposure windows } \\
49-60 \text { months prior to death/index }\end{array}$} & \multicolumn{6}{|l|}{ Colorectal cancer ${ }^{\mathrm{a}, \mathrm{b}}$} \\
\hline & \multirow{2}{*}{$\begin{array}{l}\text { Cases-N (statin use \%) } \\
17(94.1)\end{array}$} & \multirow{2}{*}{$\frac{\text { Controls-N (statin use \%) }}{17(76.5)}$} & \multicolumn{2}{|c|}{$\mathrm{RR}(95 \% \mathrm{CI})$} & \multicolumn{2}{|c|}{$\mathrm{RD}(95 \% \mathrm{CI})$} \\
\hline & & & 1.23 & $(0.97,1.56)$ & 0.18 & $(0.00,0.36)$ \\
\hline $43-48$ months prior to death/index & $31(83.9)$ & $31(83.9)$ & 1.00 & $(0.83,1.20)$ & 0.00 & $(-0.15,0.15)$ \\
\hline $37-42$ months prior to death/index & $42(88.1)$ & $42(88.1)$ & 1.00 & $(0.88,1.14)$ & 0.00 & $(-0.11,0.11)$ \\
\hline 33-36 months prior to death/index & $55(87.3)$ & $55(85.5)$ & 1.02 & $(0.90,1.16)$ & 0.02 & $(-0.09,0.13)$ \\
\hline 29-32 months prior to death/index & $64(90.6)$ & $64(85.9)$ & 1.05 & $(0.95,1.17)$ & 0.05 & $(-0.04,0.14)$ \\
\hline 25-28 months prior to death/index & $72(86.1)$ & $72(86.1)$ & 1.00 & $(0.89,1.13)$ & 0.00 & $(-0.10,0.10)$ \\
\hline 22-24 months prior to death/index & $87(82.8)$ & $87(82.8)$ & 1.00 & $(0.90,1.12)$ & 0.00 & $(-0.09,0.09)$ \\
\hline 19-21 months prior to death/index & $100(84.0)$ & $100(82.0)$ & 1.02 & $(0.93,1.13)$ & 0.02 & $(-0.06,0.10)$ \\
\hline 16-18 months prior to death/index & $106(80.2)$ & $106(84.0)$ & 0.96 & $(0.86,1.06)$ & -0.04 & $(-0.12,0.04)$ \\
\hline 13-15 months prior to death/index & $118(80.5)$ & $118(87.3)$ & 0.92 & $(0.84,1.02)$ & -0.07 & $(-0.15,0.01)$ \\
\hline 10-12 months prior to death/index & $128(78.1)$ & $128(86.7)$ & 0.90 & $(0.81,1.00)$ & -0.09 & $(-0.17,0.00)$ \\
\hline 7-9 months prior to death/index & $138(76.1)$ & $138(81.9)$ & 0.93 & $(0.83,1.04)$ & -0.06 & $(-0.15,0.03)$ \\
\hline 4-6 months prior to death/index & $148(75.0)$ & $148(83.8)$ & 0.90 & $(0.80,1.00)$ & -0.09 & $(-0.17,0.00)$ \\
\hline 3 months prior to death/index & $162(61.1)$ & $162(79.0)$ & 0.77 & $(0.68,0.88)^{*}$ & -0.18 & $(-0.27,-0.09)^{*}$ \\
\hline 2 months prior to death/index & $171(56.1)$ & $171(79.5)$ & 0.71 & $(0.61,0.81)^{*}$ & -0.23 & $(-0.32,-0.14)^{*}$ \\
\hline 4-3 weeks prior to death/index & $185(42.7)$ & $185(77.8)$ & 0.55 & $(0.46,0.66)^{*}$ & -0.35 & $(-0.44,-0.26)^{*}$ \\
\hline 2 weeks prior to death/index & $192(34.9)$ & $192(77.1)$ & 0.45 & $(0.37,0.55)^{*}$ & -0.42 & $(-0.51,-0.36)^{*}$ \\
\hline 1 week prior to death/index & $195(30.8)$ & $195(77.4)$ & 0.40 & $(0.32,0.49)^{*}$ & -0.47 & $(-0.55,-0.38)$ \\
\hline
\end{tabular}

medication that should be considered for discontinuation [24]. Given the lack of clinical guidelines on statin therapy discontinuation in the Irish setting, these studies may prove useful in the clinical decision making process in regards to medication received by patients who are approaching death.

The decision to discontinue statin treatment approaching the end-of-life may be the result of a decision to reduce pharmacotherapeutic burden on the patient. However, there may also be other clinical reasons for deciding to cease statins. Cancer cachexia is associated with changes in body composition and loss of muscle mass resulting in worsening functional performance, reduced quality of life, and reduced prognosis [25]. Cachexia affects approximately $50 \%$ of all cancer patients, and this figure increases to over $80 \%$ in the last 2 weeks of life [26]. Preclinical studies showed that treatment of animal models with simvastatin caused a further decrease in muscle mass and suggested that statin treatment in cachectic patients should be used with caution [27, 28]. Malnutrition and cachexia in chemotherapy patients have been expressed as reasons for discontinuing lipid-modifying medications [5]. In addition, statins are metabolised in the liver by the cytochrome P450 enzyme family, which are altered by chemotherapeutic agents used in colorectal cancer, such as capecitabine and irinotecan, which may result in altered drug metabolism [29]. As well as reducing adverse physical effects on the cancer patient, prescribing doctors may be influenced by the psychological effects of ceasing a preventative medication. Physicians may choose not to discuss the stopping of preventative medications, in order to avoid prognostic estimates and emotional distress for the patient [11]. However, discussion of potential benefits and harms of continuing statin treatment may provide an opportunity for patient centered-decision making [23].

Another important implication of this study is in the investigation of statin exposure and cancer outcomes. The results from our study suggest that a poor cancer prognosis may influence the probability of remaining exposed to statin treatment. This is known as reverse causation and can lead to biased estimates of associations between post-diagnosis drug exposure and cancer outcomes [30]. Reverse causation has been highlighted as a threat to the validity of nonrandomized studies, and should be dealt with through the 
Fig. 2 Probability of continued statin use prior to breast cancer specific death

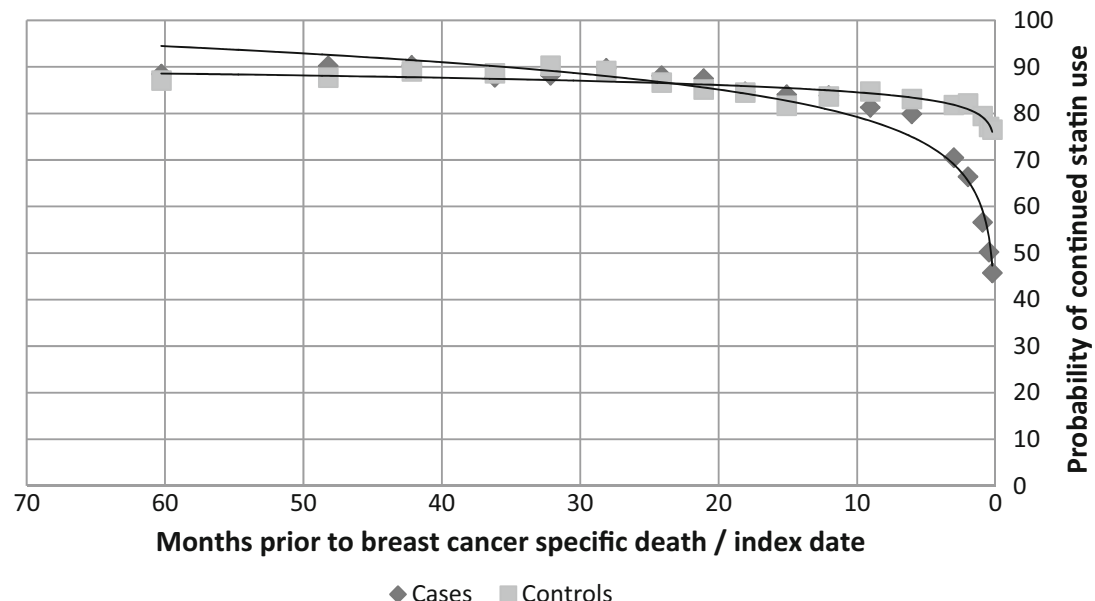

Cases Controls inclusion of an exposure lag period, so as to exclude the exposure window prior to death [30]. Some studies investigating statin exposure and cancer outcomes do not consider the fact that a cancer diagnosis or changes in cancer prognosis may influence the probability of remaining exposed to statins [31-33]. The results from our study show that proximity to death does in fact influence statin exposure, even after matching on predictors of prognosis (age, stage). Our study shows that rates of statin continuation decline prior to death from breast or colorectal cancer, when compared to matched cancer survivors. This occurs in the year prior to death, with rates of statin continuation becoming significantly lower from 3 months prior to a breast or colorectal cancer. This suggests a minimum 3-month lag of statin exposure may be sufficient for reduction in reverse causation bias.

Our study used prospectively collected, high qualitylongitudinal prescription information to compare the initiation and continuation of statin treatment in patients who died of breast or colorectal cancer, as compared to those who survived. This allowed us to differentiate between patterns of statin use in breast and colorectal cancer patients, and also in patients who are approaching the end of their lives. A limitation of this study is that prescription refill data is a proxy for medication use, and it may not represent patients who were admitted to hospice care. A study of Irish colorectal cancer patients showed that approximately $13 \%$ of end-of-life care occurred in a hospice facility [34]. In addition, we do not have information on indication for statins or other medications in these patients, or reasons for ceasing treatment. Finally, our study population is defined by eligibility for the GMS scheme, and therefore may over-represent patients who are older and of lower socioeconomic status.

To conclude, a significant proportion of breast and colorectal cancer patients will cease statin treatment as they approach a cancer-specific death. The decline in statin-use occurs up to 1 year prior to death, but becomes statistically significant at least 3 months prior to death. This decline in statin use may be due to different patient or clinical factors, such as a shift in treatment paradigm, or the development of contraindications [22]. To our knowledge, this is first study to describe longitudinally the statin exposure in a cohort of breast or colorectal cancer patients in the time prior to death, compared to
Fig. 3 Probability of continued statin use prior to colorectal cancer specific death

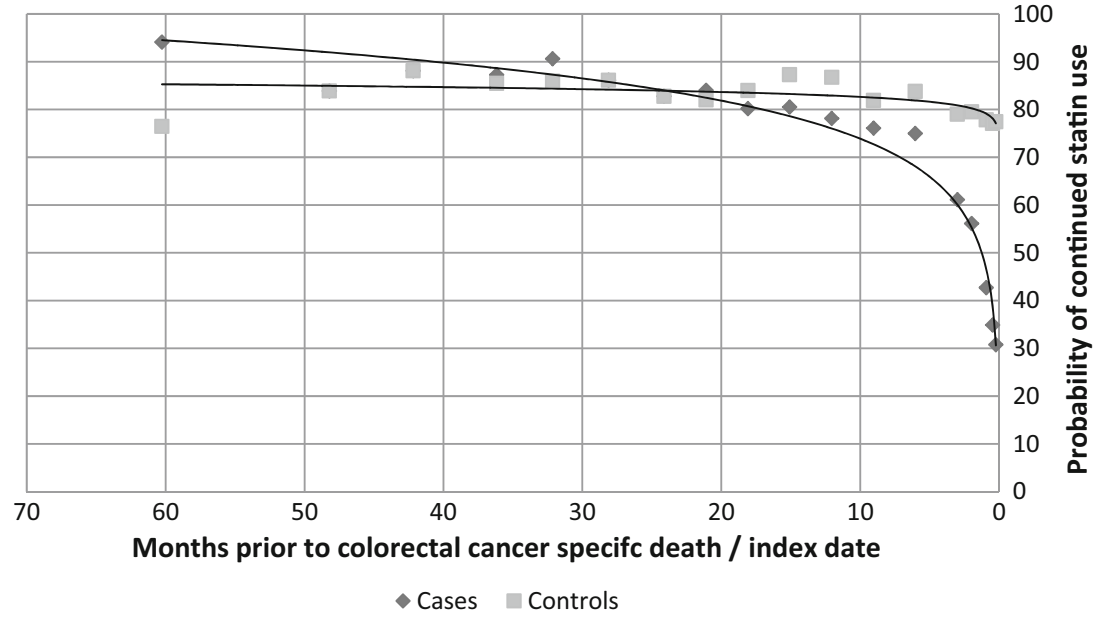


matched cancer-survivors. The results of this study have important implications for (i) the statistical analyses of studies investigating post-diagnostic statin exposure and cancer outcomes; our results suggest that the inclusion of an exposure lag time is vital to account for reverse causation in these studies, and (ii) for the shared decision making process at the end of life, whereby there may be an opportunity to re-evaluate medication burden in this patient group.

Acknowledgements We would like to thank the National Cancer Registry Ireland and the Irish Health Services Executive Primary Care Reimbursements Services for providing access to the data upon which this study was based. In particular, we are grateful to the Data Team at the National Cancer Registry Ireland for linking the datasets and Dr. Sandra Deady and Mr. Christopher Brown for preparing these for analysis. The interpretation and reporting of these data are the responsibility of the authors and should in no way be seen as the official policy or interpretation of the National Cancer Registry Ireland or the Irish Health Services Executive Primary Care Reimbursements Services.

\section{Compliance with ethical standards}

Financial support This work was supported by the Irish Cancer Society Collaborative Cancer Research Centre BREAST-PREDICT [CCRC13GAL to K Bennett, TI Barron]. L Murphy and A Smith's positions are funded by the Irish Cancer Society Collaborative Cancer Research Centre BREAST-PREDICT [CCRC13GAL]. TI Barron's [ICE/2011/9] and K Bennett's [RLA/2015/1579] position was funded by the Health Research Board Ireland. The Health Research Board Ireland and the Irish Cancer Society had no role in the study design; collection, analysis, and interpretation of data; writing of the report; or the decision to submit for publication.

Disclosures None.

Open Access This article is distributed under the terms of the Creative Commons Attribution-NonCommercial 4.0 International License (http:// creativecommons.org/licenses/by-nc/4.0/), which permits any noncommercial use, distribution, and reproduction in any medium, provided you give appropriate credit to the original author(s) and the source, provide a link to the Creative Commons license, and indicate if changes were made.

\section{References}

1. Holmes HM, Hayley D, Alexander G, Sachs GA (2006) REconsidering medication appropriateness for patients late in life. Arch Intern Med 166:605-609. doi:10.1001/archinte.166.6.605

2. LaRosa JC, He J, Vupputuri S (1999) Effect of statins on risk of coronary disease: a meta-analysis of randomized controlled trials. JAMA 282:2340-2346. doi:10.1001/jama.282.24.2340

3. Spencer FA, Allegrone J, Goldberg RJ et al (2004) Association of Statin Therapy with outcomes of acute coronary syndromes: the GRACE study. Ann Intern Med 140:857-866. doi:10.7326/00034819-140-11-200406010-00006

4. Bayliss EA, Bronsert MR, Reifler LM et al (2013) Statin prescribing patterns in a cohort of cancer patients with poor prognosis. $\mathrm{J}$ Palliat Med 16:412-418. doi:10.1089/jpm.2012.0158
5. Tanvetyanon T, Choudhury AM (2006) Physician practice in the discontinuation of statins among patients with advanced lung cancer. J Palliat Care 22:281-285

6. Bayliss EA, Reifler LM, Zeng C et al (2014) Competing risks of cancer mortality and cardiovascular events in individuals with multimorbidity. J Comorbidity 4:29-36

7. Silveira MJ, Kazanis AS, Shevrin MP (2008) Statins in the last six months of life: a recognizable, life-limiting condition does not decrease their use. J Palliat Med 11:685-693. doi:10.1089/jpm.2007.0215

8. Fede A, Miranda M, Antonangelo D et al (2011) Use of unnecessary medications by patients with advanced cancer: cross-sectional survey. Support Care Cancer Off J Multinatl Assoc Support Care Cancer 19:1313-1318. doi:10.1007/s00520-010-0947-1

9. Stavrou EP, Buckley N, Olivier J, Pearson S-A (2012) Discontinuation of statin therapy in older people: does a cancer diagnosis make a difference? An observational cohort study using data linkage. BMJ Open. doi:10.1136/bmjopen-2012-000880

10. Richardson DB, Cole SR, Chu H, Langholz B (2011) Lagging exposure information in cumulative exposureresponse analyses. Am J Epidemiol 174:1416-1422. doi:10.1093/aje/kwr260

11. Mullvain JA, Kozak KR, Moody JS, Campbell TC (2015) Statin use in cancer patients with brain metastases: a missed communication opportunity at the end of life. Support Care Cancer Off J Multinatl Assoc Support Care Cancer 23:26432648. doi:10.1007/s00520-015-2624-x

12. Jemal A, Bray F, Center MM, et al (2011) Global cancer statistics. CA Cancer J Clin 61:69-90. doi:10.3322/caac.20107

13. Barron TI, Flahavan EM, Sharp L et al (2014) Recent prediagnostic aspirin use, lymph node involvement, and 5-year mortality in women with stage I-III breast cancer: a Nationwide population-based cohort study. Cancer Res 74:4065-4077. doi:10.1158/0008-5472. CAN-13-2679

14. Data quality and completeness at the Irish National Cancer Registry | National Cancer Registry Ireland. http://www.ncri. ie/publications/statistical-reports/data-quality-and-completenessirish-national-cancer-registry. Accessed 20 Feb 2015

15. WHOCC - ATC/DDD Index. http://www.whocc.no/atc ddd index/. Accessed 9 Feb 2015

16. Howlader N, Ries LAG, Mariotto AB et al (2010) Improved estimates of cancer-specific survival rates from population-based data. J Natl Cancer Inst 102:1584-1598. doi:10.1093/jnci/djq366

17. Stuart EA (2010) Matching methods for causal inference: a review and a look forward. Stat Sci Rev J Inst Math Stat 25:1-21. doi:10.1214/09-STS313

18. Barron TI, Cahir C, Sharp L, Bennett K (2013) A nested case-control study of adjuvant hormonal therapy persistence and compliance, and early breast cancer recurrence in women with stage I-III breast cancer. Br J Cancer 109:15131521. doi: $10.1038 /$ bjc. 2013.518

19. Tevaarwerk AJ, Gray R, Schneider BP et al (2013) Survival in metastatic recurrent breast cancer after adjuvant chemotherapy: little evidence for improvement over the past three decades. Cancer 119:1140-1148. doi:10.1002/cncr.27819

20. Cutsem EV, Cervantes A, Nordlinger B, Arnold D (2014) Metastatic colorectal cancer: ESMO clinical practice guidelines for diagnosis, treatment and follow-up. Ann Oncol 25:iii1-iii9. doi:10.1093/annonc/mdu260

21. Cleveland WS (1979) Robust locally weighted regression and smoothing scatterplots. J Am Stat Assoc 74:829-836. doi:10.2307/2286407

22. LeBlanc TW, McNeil MJ, Kamal AH et al (2015) Polypharmacy in patients with advanced cancer and the role of medication discontinuation. Lancet Oncol 16:e333-e341. doi:10.1016/S1470-2045(15 )00080-7 
23. Kutner JS, Blatchford PJ, Taylor DH et al (2015) Safety and benefit of discontinuing statin therapy in the setting of advanced, lifelimiting illness: a randomized clinical trial. JAMA Intern Med 175:691-700. doi:10.1001/jamainternmed.2015.0289

24. Lindsay J, Dooley M, Martin J et al (2015) The development and evaluation of an oncological palliative care deprescribing guideline: the "OncPal deprescribing guideline"support care cancer off. J Multinatl Assoc Support Care Cancer 23. doi:10.1007/s00520-014-2322-0

25. Fearon K, Strasser F, Anker SD et al (2011) Definition and classification of cancer cachexia: an international consensus. Lancet Oncol 12:489-495. doi:10.1016/S1470-2045(10)70218-7

26. Epidemiology | Epidemiology | Cancer Cachexia. http://www. cancercachexia.com/epidemiology-hcp. Accessed 22 Feb 2016

27. Muscaritoli M, Costelli P, Bossola M et al (2003) Effects of simvastatin administration in an experimental model of cancer cachexia. Nutr Burbank Los Angel Cty Calif 19:936-939

28. Molfino A, Costelli P, Aversa Z et al (2007) Statins, coenzyme Q10, and cachexia: what's the link? Am J Cardiol 100:1497-1498. doi:10.1016/j.amjcard.2007.07.007
29. Hall PS, Lord SR, El-Laboudi A, Seymour MT (2010) Non-cancer medications for patients with incurable cancer: time to stop and think? Br J Gen Pr 60:243-244. doi:10.3399/bjgp10X483887

30. Chubak J, Boudreau DM, Wirtz HS et al (2013) Threats to validity of nonrandomized studies of postdiagnosis exposures on cancer recurrence and survival. J Natl Cancer Inst 105:1456-1462. doi:10.1093/jnci/djt211

31. Murtola TJ, Visvanathan K, Artama M et al (2014) Statin use and breast cancer survival: a Nationwide cohort study from Finland. PLoS One. doi:10.1371/journal.pone.0110231

32. Chae YK, Valsecchi ME, Kim J et al (2011) Reduced risk of breast cancer recurrence in patients using ACE inhibitors, ARBs, and/or statins. Cancer Investig 29:585-593. doi:10.3109/07357907.2011.616252

33. Desai P, Lehman A, Chlebowski RT et al (2015) Statins and breast cancer stage and mortality in the women's health initiative. Cancer Causes Control CCC. doi:10.1007/s10552-015-0530-7

34. Céilleachair AÓ, Finn C, Deady S et al (2010) Have developments in palliative care services impacted on place of death of colorectal cancer patients in Ireland? A population-based study. Ir J Med Sci 180:91-96. doi:10.1007/s11845-010-0607-y 